\title{
PUPUK ORGANIK CAIR KOMBINASI LIMBAH ENCENG GONDOK DAN BUAH BUSUK PADA TANAMAN KANGKUNG DARAT (Ipomea reptans oil)
}

\author{
I.A.K Pramushinta \\ FMIPA, Universitas PGRI Adi Buana Surabaya \\ Email: iak.pramushinta@unipasby.ac.id
}

\begin{abstract}
Abstrak
Enceng gondok (Eichornia crassipes) merupakan salah satu jenis tumbuhan air memiliki laju pertumbuhan yang cepat sehingga disebut sebagai gulma yang mengganggu wilayah perairan. Enceng gondok dapat dimanfaatkan sebagai pupuk cair yang berguna terhadap kebutuhan unsur hara tanaman. Buah-buahan busuk yang digunakan papaya, jambu biji dan pisang mas merupakan campuran pembuatan pupuk organik cair. Penelitian ini digunakan untuk mengetahui pengaruh pupuk organik cair dengan mengkombinasi tanaman enceng gondok dan buah busuk pada tanaman kangkung darat (Ipomea reptans oil). Parameter yang diukur adalah tinggi tanaman dan bobot tanaman kangkung darat pada hari ke 7,14,21 dan 28 hari setelah masa tanam, dengan menggunakan 4 perlakuan dengan konsentrasi berbeda yaitu PO (tanpa POC), P1 (100ml POC), P2 (200ml POC), dan P3 (300ml POC). Hasil analisis menunjukkan bahwa signifikan $(p<0,005)$ sehingga pembuatan POC dari limbah enceng gondok dan buah busuk dapat meningkatkan pertumbuhan pada tanaman kangkung darat (Ipomea reptans oil).
\end{abstract}

Kata kunci : POC, enceng gondok, buah busuk, kangkung darat

\begin{abstract}
Water hyacinth (Eichornia crassipes) is a type of aquatic plant that has a fast growth rate so it is referred to as a weed that disturbs water areas. Water hyacinth can be used as a liquid fertilizer that is useful against the needs of plant nutrients. Rotten fruits used by papaya, guava and banana are a mixture of making liquid organic fertilizer. This study was used to determine the effect of liquid organic fertilizer by combining water hyacinth plants and rotten fruit on ground kale plants (Ipomea reptans oil). The parameters measured were plant height and weight of ground water spinach plants on the day 7,14,21 and 28 days after planting, using 4 treatments with different concentrations namely PO (without POC), P1 (100ml POC), P2 (200ml POC), and P3 (300ml $P O C)$. The results of the analysis showed that it was significant $(p<0.005)$ so that the manufacture of POC from water hyacinth waste and rotten fruit could increase growth in land kale plants (Ipomea reptans oil).
\end{abstract}

Keywords : POC, water hyacinth, rotten fruit, ground water spinach 


\section{PENDAHULUAN}

Pupuk adalah suatu bahan atau material yang digunakan untuk mengubah sifat fisik, kimia dan biologi tanah sehingga menjadi lebih baik bagi pertumbuhan tanaman. Material pupuk dapat berupa bahan organik (pupuk organik) dan bahan non organik (pupuk anorganik). Pupuk organik yang dimanfaatkan untuk pembuatan pupuk organik cair yaitu tanaman enceng gondok dan buah busuk. Berdasarkan bentuknya, pupuk organik dibedakan menjadi 2 yaitu pupuk cair dan pupuk padat (Hadisuwito, 2007) ${ }^{[1]}$.

Pupuk organik cair memiliki kelebihan kandungan antara lain mampu menyediakan unsur hara lengkap yang dibutuhkan oleh tanaman untuk tumbuh, memperbaiki struktur tanah, memperbaiki kehidupan suatu mikroorganisme dalam tanah, memperbaiki kehidupan mikroorganisme dalam tanah pembagiannya dapat lebih merata dan mudah digunakan.

Penggunaan pupuk organik dan anorganik digunakan dengan dosis yang sesuai agar kebutuhan hara untuk tanaman terpenuhi sehingga diharapkan dapat menekan dan meminimalkan penggunaan pupuk anorganik. Kandungan POC harus mempunyai kandungan pupuk $\mathrm{N}, \mathrm{P}, \mathrm{K}$ terhadap pertumbuhan tanaman kangkung darat. (Puspadewi., W., 2016) ${ }^{[2]}$

Pupuk N, P, K merupakan unsur hara makro yang banyak diserap tanaman terutama pada vase vegetative sehingga pupuk $\mathrm{N}, \mathrm{P}, \mathrm{K}$ sangat sangat dibutuhkan untuk pertumbuhan tanaman terutama dalam merangsang pembentukan tinggi tanaman, pembesaran diameter batang serta bobot tanaman (Jumini dkk., 2009) ${ }^{[3]}$

Kangkung tergolong jenis sayuran popular di masyarakat dan memiliki daya tarik pembudidaya tanaman kangkung serta memiliki unsur hara untuk menyuburkan tanaman. Kangkung juga memiliki manfaat sebagai pencegahan anemia, diabetes, jantung, kolesterol dan peningkatan system imun tubuh. (Edi, 2015) ${ }^{[4]}$

Tujuan penelitian ini dilakukan untuk mengetahui adanya pengaruh pemberian pupuk organik dari tanaman enceng gondok dan buah busuk terhadap tinggi tanaman dan bobot tanaman kangkung darat (Ipomea reptans oil).

\section{METODE PENELITIAN}

Penelitian ini untuk mengetahui pengaruh pupuk organik cair (POC) dengan tanaman enceng gondok dan buah busuk pada tanaman kangkung darat.

\section{Alat Bahan}

Alat yang digunakan Blender, Neraca Analitik, Polybag ukuran $10 \times 10 \mathrm{~cm}$, Gelas ukur 100 ml, Penggaris, Spidol, tong plastik.

Bahan yang digunakan enceng gondok, buah busuk (papaya, jambu biji dan pisang mas), EM4, Gula Merah, benih tanaman kangkung darat, pupuk, sekam bakar, sekam matang, pupuk urea, air.

\section{Tempat dan Waktu Penelitian}

Penelitian dilaksanakan di Green House Program Studi Biologi Universitas PGRI Adi Buana Surabaya.

\section{Pembuatan POC}

Proses pembuatan POC yang berasal dari tanaman eceng gondok dan buah-buahan yang telah busuk masing-masing sebanyak 1 $\mathrm{kg}$ kemudian dicampur $1 / 2 \mathrm{~kg}$ gula merah, tambahkan EM4 1 L dan air sebanyak $2 \mathrm{~L}$ kedalam tong plastik, setelah itu diaduk rata sehingga tercampur rata, lalu ditutup rapat dan diamkan selama 4 minggu sampai ditandai dengan terdapatnya proses fermentasi, larutan berbau, dan terdapat lapisan jamur putih dipermukaan. POC 
disaring sampai bersih dan disimpan dalam botol tertutup.

\section{Penanaman Benih Kangkung Darat}

Pemilihan Benih yang telah berkecambah atau berumur 30 hari setelah semai lalu dipindah ke polybag. Media tanam dibuat dengan campuran tanah, sekam matang, sekam bakar, dan pupuk urea.

\section{Pemupukan}

Pemupukan dengan menggunakan pupuk organik cair dari limbah buah busuk dan eceng gondok. Pupuk diencerkan dengan air. Pengenceran dilakuakan sesuai perlakuan yang akan diteliti, yakni pupuk organik cair kombinasi limbah buah busuk dan eceng gondok :

- P0 : Kontrol (Menggunakan air $100 \mathrm{ml}$ )

- P1 : Perlakuan dengan kadar 100 ml POC

- P2 : Perlakuan dengan kadar $200 \mathrm{ml}$ POC

- P3 : Perlakuan dengan kadar $300 \mathrm{ml}$ POC Untuk pemberian pupuk organik cair kombinasi limbah buah busuk dan eceng gondok dilakukan 1 minggu setelah semaian pindah polybag sebanyak dengan cara disiramkan langsung pada tanah dalam polybag tersebut. Pemberian pupuk selanjutnya dilakukan $3 \mathrm{x}$ dalam 1 minggu selama 30 hari hingga panen untuk dilakukan pengukuran tinggi dan bobot pada tanaman kangkung darat. Penyiraman dilakukan di waktu sore hari.

\section{HASIL DAN PEMBAHASAN}

Berdasarkan hasil penelitian yang telah dilakukan untuk melihat adanya pengaruh pemberian pupuk organik cair dari tanaman enceng gondok dan buah busuk terhadap tinggi tanaman dan bobot tanaman pada kangkung darat.

Berdasarkan hasil pengamatan hari ke $7,14,21$ dan 28 hari yang menunjukkan adanya perbedaan signifikan $(p<0,005 \%)$ pada uji analisa varian rancangan acak lengkap (RAL). Adapun hasil pengamatan pengaruh POC terhadap tanaman kangkung darat dapat dilihat pada Tabel 1.

Tabel 1. Pengaruh POC terhadap tanaman kangkung darat

\begin{tabular}{|c|c|c|c|}
\hline No & Parameter & Hari ke- & Rerata \\
\hline \multirow[t]{4}{*}{1} & \multirow{4}{*}{$\begin{array}{l}\text { Tinggi } \\
\text { tanaman }\end{array}$} & 7 & $11,29 \mathrm{~cm}$ \\
\hline & & 14 & $15,58 \mathrm{~cm}$ \\
\hline & & 21 & $17,9 \mathrm{~cm}$ \\
\hline & & 28 & $24 \mathrm{~cm}$ \\
\hline \multirow[t]{4}{*}{2} & \multirow{4}{*}{$\begin{array}{l}\text { Bobot } \\
\text { tanaman }\end{array}$} & 7 & $59,21 \mathrm{gr}$ \\
\hline & & 14 & $69,3 \mathrm{gr}$ \\
\hline & & 21 & $78 \mathrm{gr}$ \\
\hline & & 28 & $94 \mathrm{gr}$ \\
\hline
\end{tabular}

pengaruh pupuk organik cair (POC) tanaman enceng gondok dan buah busuk terhadap tanaman kangkung darat pada tinggi tanaman dan bobot tanaman kangkung darat mengalami peningkatan. Sehingga dapat disimpulkan bahwa pemberian pupuk organik cair tersebut sangat efektif serta menunjukkan pengaruh yang signifikan dalam taraf $<5 \%$.

\section{KESIMPULAN}

Pemberian pupuk organik cair terbuat dari tanaman enceng gondok dan buah busuk sangat efektif terhadap pertumbuhan kangkung darat (Ipomea reptans oil).

\section{REFERENSI}

Edi, Syafri, 2014. Pengaruh Pemberian Pupuk Organik Terhadap Pertumbuhan dan Hasil Tanaman Kangkung Darat (Ipomea Reptans,Poir). Balai Pengujian Teknologi Pertanian Vol 3 No 1.

Hadisuwito, S., 2007. Membuat Pupuk Organik Cair. PT. Agro Media Pustaka : Jakarta Selatan 
WAHANA

Volume 72, Nomor 1, 1 Juni 2020

Juminu, Nurhayati, dan Murzani, 2011, Efek Kombinasi Pupuk N, P, K dan Cara Pemupukan Terhadap Pertumbuhan dan Hasil Jangung Manis.J. Floratek, 6:165-170.

Puspadewi., S., 2016, Pengaruh konsentrasi pupuk organik cair (POC) dan dosis pupuk $\mathrm{N}, \mathrm{P}, \mathrm{K}$ tehadap pertumbuhan dan hasil tanaman jagung manis (Zea mays L. var Rugosa Bonaf) kultivar Talenta. Jurnal Kultivasi Vol 15 No 3. Universitas Padjajaran 